\title{
JUGANDO CON FUEGO El fuego como realidad metafísica
}

\author{
Mariano Brasa Díez \\ Universidad Autónoma de Madrid
}

\section{RESUMEN:}

Cuando Escoto Eriúgena elige el fuego como elemento determinante para su metafísica no está haciendo nada más que conjugar una serie de pensamientos que toma de aquí y de allá, de la Escritura y de los Padres, con sus propias convicciones. Va enhebrando un estudio del fuego dentro de un contexto físico, para luego dar el salto sobre el campo metafísico. El fuego deja de ser fuego y se convierte, por encima de la historia (tierra), de la ética (agua), y de la física (aire), en una metafísica que es teología (fuego)

Palabras clave: J.S. Eriugena, fuego, metafísica, teofanías, luz, calor.

\begin{abstract}
When Eriugena choses the fire as determinate element for his metaphysics he is just doing a series of thinkings that he takes from here, from there, from the Holly Scriptures and from the Holly Fathers, with his own convictions. He is threading a study of the fire in a physic context and then jumps through the metaphysic field. The fire is no fire and it becomes, above the history (earth), the ethic (water), the physic (air) in a metaphysic that is theology (fire).
\end{abstract}

Key words: J.S. Eriugena, fire, metaphysic, theophanies, light, heat.

\section{INTRODUCCIÓN}

En una obra justamente famosa, El psicoanálisis del fuego, escribe G. Bachelard: «Cuando se pregunta a las personas cultas, digamos a los sabios, como yo le he hecho muchas veces: '¿Qué es el fuego?', se reciben respuestas vagas o tautológicas, que repiten inconscientemente las teorías filosóficas más antiguas y las más quiméricas». ${ }^{1}$ Los que dan estas respuestas no dejan de tener excusas. El mismo Bachelard reconocía que «el fuego no ha encontrado todavía su ciencia como la ha encontrado la electricidad. Ha quedado en el espíritu precientífico como un fenómeno complejo que procede, a la vez, de la química y de la biología». ${ }^{2}$ De los cuatro elementos, -agua, tierra, aire y fuego- que, según la física de los Antiguos, constituyen la trama del universo, el fuego es

1 Bachelard, G., La psychanalyse du feu, París, Collection Idées (n. 73), 1968, p. 11

2 Ibíd., o. c., p. 104. 
el único que la ciencia moderna se ha olvidado de analizar, pesar, medir en todos los sentidos. Tal vez sea debido a que el fuego ha sido dejado a un lado del progreso científico, por lo que conserva sobre nuestro espíritu un extraño poder de seducción. Por muchas razones el fuego sigue siendo lo que era para los Antiguos: el elemento noble. Los Kephalaia cuando hablan del fuego se refieren básicamente a Zoroastro. Zoroastro representa el fuego celeste-viviente dentro y fuera del todo[...] Zoroastro mismo es el fuego, lo primero y lo más antiguo en las consideraciones de los Kephalaia. Heráclito se mueve en el mismo ámbito y nos dice que el fuego es como los dioses, eterno. Todo es fuego $<30>$ y al ser eterno no se puede comprender como origen de otra cosa o como una explicación científica del cosmos. El fuego está relacionado con to alto -los dioses-y con el sol $\langle 99\rangle$ opuesto a los Erinias de la tierra $\langle 94\rangle$. Fuego, relacionado con sus propios rayos $\langle 64,65\rangle$ con lo divino y el sol $<11>$. Dioses-fuego-sol es el día $<67>[. .$.$] ; Dioses-fuego-día es el logos supre-$ mo, la suprema sabiduría, palabra o razón $\langle 32,1,78>$. Es la sabiduría en cuanto es peculiar de dioses-fuego[...] separada de todo $<108>$. Es lo verdadero o uno-todo $<50\rangle$. Los hombres son logos u opiniones $\langle 28,70\rangle$, son logos que dividen-separan. ${ }^{3}$ En una época que se quiere igualitaria, el fuego sigue siendo un aristócrata. Habría que decir todavía más: en un mundo que se cree desacralizado, el fuego no ha perdido totalmente su carácter sagrado: Lo encontramos asociado siempre a las grandes liturgias locales, nacionales e internacionales: arde ante la tumba del soldado desconocido; flamea en el gran pebetero de los juegos olímpicos; en cualquier fiesta que se precie está presente el fuego y, siempre está encendido en las iglesias.

El propósito de este preámbulo no es otro que buscar la indulgencia para quien, en las especulaciones medievales sobre el fuego, que va a ser el objeto de su estudio, podrá parecerles ingenuo, impuro, quimérico. ¿Cómo podríamos condenar sin apelación semejantes especulaciones nosotros que, si creemos a Gaston Bachelard, no estamos seguros de haber salido de la edad precientífica?. El autor que pretendo estudiar ejerció sobre su tiempo (el tercer cuarto del siglo IX) y sobre su entorno (reinado de Carlos el Calvo) una influencia considerable. Ocupa un lugar preeminente en la Historia de la Filosofía. Juan Scoto Eriúgena escribió sobre el fuego cosas realmente importantes, de una belleza exquisita; la misma belleza que emplea cuando habla del mar, del agua, de la luz [...], de la naturaleza. Sin embargo han sido poco estudiadas. Lo que pretendo hacer en este trabajo es precisamente eso: estudiar la doctrina de Scoto Eriúgena sobre el fuego y ver cómo, a lo mejor al final del trabajo, podemos hablar de una «metafísica del fuego». Por otra parte tendremos que examinar los textos sagrados y profanos que han sido los que delimitaron el campo y me dieron todos los elementos necesarios para convertir en juego una investigación. Se trata de un juego cuyo elemento principal es el fuego y puede resultar peligroso, sobre todo, si el maestro pirotécnico es del siglo IX y se llama Juan Scoto Eriúgena.

3 Los números correspondientes a los fragmentos de Heráclito los he puesto dentro de los signos mayor quemenor que $\diamond$ para no confurdirlos con las notas. Sigo el orden de los fragmentos de Diels-Kranz. Diels, H.,-Kranz, W., Die Fragmente der Vorsokratiker. Berlín, 1951. He tenido también presente la traducción de L. Farre, Heráclito. Fragmentos. Aguilar, Madrid, 1982 y, en alguna ocasión me he servido también de la traducción de García-Calvo, J., Heráclito. Razón común. Ed. Crítica, ordenación, traducción y comentario de los restos del libro de Heráclito. Lucina, Madrid, 1985, y también de García Bacca, J.D.,Fragmentos filosóficos de los presocráticos, Caracas, 1955. 


\section{EN BUSCA DEL FUEG0}

¿Por qué «Metafísica del fuego»? Si utilizo esta expresión es, primero y fundamental, porque quiero descartar la física en cuanto tal. A pesar de todo, no hay que creer que Eriúgena tratara de construir, a su manera y con los medios de que disponía, una física del fuego, comparable a la «física de la luz» que más tarde elaboraría Roberto Grosseteste. Al filósofo irlandés no le interesa el fuego más que en la medida en que le proporciona metáforas para ilustrar sus tesis filosóficas sobre Dios, el hombre, el universo. Esto es lo que yo llamaré «metafísica del fuego». Tal vez sea la primera vez que la fórmula se relaciona con Scoto Eriúgena, pero no es la primera vez que se emplea, porque ya Gaston Bachelard habló en el año 1968 de las «metafísicas del fuego». ${ }^{4}$ Otra fórmula, «dialéctica del fuego» ${ }^{5}$ pudiera habernos sido útil. Pero, después de todo, poco importan las fórmulas. Lo importante es tratar de comprender la parte filosófica que Eriúgena supo sacar de su observación del fuego: observación ingenua, es verdad, pero rodeada de un halo de conceptos que podemos calificar de precientíficos, a condición de no olvidar quie, para los hombres del siglo IX, representaban la ciencia misma.

¿Qué decir de los textos que le sirvieron al filósofo del siglo IX para trazar los rasgos de esta metafísica?. Bastará recordar algunos textos, sagrados o profanơs, que tratan del fuego. Algunos de ellos pudieron influir y estimular la reflexión erigeniana. El atractivo de los filósofos por el fuego se inscribe en una tradición que se remonta hasta Heráclito de Éfeso que veía en el fuego la moneda de oro que preside todos los cambios y mutaciones de los elementos. ${ }^{6}$ Heráclito menciona el fuego de una manera que nos obliga a entenderlo como ser, còmo estado[...]. Heráclito se imagina el fuego, el mar, la tierra y la tempestad como objetos que sólo, en apariencia, son y perduran, como si quisieran engañar al espíritu que reconoce y que, sustraídos a la vista, no son otra cosa que eterno e inquieto fluir y devenir, el uno como los otros. El fuego, para Heráclito, no tiene que ser considerado como una sustancia, como un arché, sustancia de la que proceden todas las cosas, sino como un trophé, es decir, como un cambio, como aparece en el fragmento $\langle 90\rangle$. Uno de los fragmentos de Heráclito, si se le adopta una conjetura propuesta por Diels, parece incluso prefigurar ciertos aspectos de esta metafísica del fuego que Eriúgena, siguiendo al Pseudo-Dionisio, debía elaborar: «Dios es día-noche, invierno-verano, guerra-paz, hartura-hambre. Toma formas variadas, exactamente como el fuego, cuando se le mezcla con aromas, se le nombre siguiendo el perfume de cada uno de ellos». ${ }^{7}$ Por su parte, los Estoicos atribuyen al fuego una función preponderante en su cosmología. Distinguen entre fuego ordinario (pyr áteknon) que consume y destruye, y fuego artista (pyr teknikón) que alimenta y construye. ${ }^{8}$ Pensaban que el mundo estaba sometido periódicamente a las caricias universales o ékpiróseis. ${ }^{9}$ Finalmente, los estoicos tendían a representar la

4 Bachelard, G., o.c., 182.

5 Ibid., o.c., pp. 167, 173, 182.

6 Diels, H. - Kranz, W., Die Fragmente der Vorsokratiker, 22, B 90.Cfr. J. Burnet, L'aurore de la philosophie grecque, Paris, 1952.

7 Hippolytus, Katá pasôn airésewn élegxos, Ix, 10,8.

8 Arnim, Stoicorum Veterum Fragmenta I, 120 (STOBEO Ec. I, 25,3, p.213, 15 W).

9 Arnim, II, 585 (Aecio, Plac. II, 4.7); 596 (Eusebio, Prep. ev. XV, 18, 1-3. 
providencia divina, y Dios mismo, bajo la forma de un fuego muy puro. ${ }^{10}$ En cuanto a los Oráculos Caldeos, tan queridos por los neoplatónicos, son un himno incesante al fuego y a la «flor del fuego». ${ }^{11}$ Resultaría inútil recordar que Escoto Eriúgena no leyó ni a Heráclito ni los Oráculos Caldeos, pero no pudo ignorar la fórmula poética «flor del fuego», porque se encuentra en una obra muy querida de Eriúgena y que él mismo comentó, De Nuptiis Philologiae et Mercurii de Marciano Capella. A lo largo del poema que abre el libro IV de esta obra, el autor, dirigiéndose a PallasAtenea, la diosa cuyos ojos son de color de fuego (lumina con color igni es), le dice:

Eres flor de fuego, noble Atenea la de ojos relumbrantes. ${ }^{12}$

Atenea es hija de Zeus. Decir que la hija de Zeus es flor de fuego, ¿no es identificar a su Padre, el dios que blande el rayo, con el fuego?

Dejo aquí mi rápido y fantasioso paseo por el inmenso camino de la literatura antigua porque las fuentes de la metafísica del fuego erigeniana no son ni la filosofía ni la poesía griegas, sino la Biblia. En el libro del Éxodo (3, 1-6) Dios se manifiesta a Moisés en una zarza ardiente. Moisés observa asombrado este curioso fenómeno: la zarza está encendida, arde y, sin embargo, no se consume. Ante tan extraño acontecimiento se dice Moisés: «voy a ver que gran visión es ésta y porqué no se consume la zarza». Este asombro y la misma pregunta de Moisés serán las reacciones de muchos pensadores cristianos ante el misterio del fuego. Sin embargo, su reflexión será menos sobre el pasaje del Éxodo que sobre un versículo del Deuteronomio $(4,24)$ : «[...] porque Yavé tu Dios, es fuego abrasador[...]», y del que se hace eco la Carta a los Hebreos $(19,29):$ «[...] porque mostró Dios ser un fuego devorador». ${ }^{13}$

Debemos libramos de creer que la Biblia haya divinizado el fuego. Sería una idolatría a la que se opone con todas sus fuerzas, como lo atestigua la visión de Elías en el libro III de los Reyes (19, 11-12): «Hubo un gran vendaval[...] pero Yavé no estaba en el viento. Y vino tras el viento un terremoto, pero no estaba Yavé en el terremoto. Vino tras el terremoto un fuego, pero no estaba Yavé en el fuego[...]». Es verdad que Yavé no está en el fuego, pero el fuego acompaña muy a menudo las teofanías del Antiguo Testamento. Basta con que Dios toque los montes para que comiencen a arder (Ps. 103, 32: «[...]toca los montes y humean»; y 143, 5: «[...]toca los montes y humearán»). Cuando

10 «Nam et Deum ipsum ignem putavit (Zenon)». (Arnim, I, 157; Augustinus, Contra Acad. III, 17, 38). «Nam Stoici ignem, id est corpus unum ex his quattuor elementis, quibus visibilis mundus hic constat, et viventem et sapientem et ipsius mundi fabricatorem atque omnium quae in eo sunt, eumque omnino ignem deum esse putaverunt» (Arnim II, 423; Augustinus, De Civitate Dei, VIII, 5).

11 Oracles chaldaïques, avec un choix de commentaires anciens, ed. E. Des Places, Paris, 1971, frag,34, 2; 35, 3; 37, 14; 42, 3. Cfr. H. Lewy. Chaldaeam Oracles and Theurgy, Paris, 1978. Según Lewy (p. 168) la flor del fuego (pyrós ánzos) es sinónimo de «la.llama sutil de un sutil entendimiento» (Oracles, fr. 1,6.).

12 «Tuque ignis flos es, cluis et glaukôpis Athéne». M. Capella, De nuptiis philologiae et Mercurii VI, 571; ed. Dick-Préaux, Leipzig 1978, p. 286-7. También en II, 206: «florem ignis» (ed. cit. p. 77.10).En las Glosae Martiani que nos transmiten tal vez un eco de la enseñanza erigeniana, se habla del fuego en los siguientes términos: «Inter Vulcanum et Ioven et Vestam hoc interest: Vulcanus est ignis devirans et consumens omnia; Vesta est ignis accomodatus in usus hominum, Iovis est ignis innocuus qui in coelo est. Iunonius, aerius, id est ignis aeris. Eraclitus autem dicit quia ille ignis stabilitat totum mundum» (Jeauneau, E., Quatre thèmes èrigéniens, Montréal-Paris, 1978, p. 164.

13 Cfr. Periphyseon V. PL. 122, 864D9, 997D9. En adelante, siempre que cite el Periphyseon, lo haré poniendo el libro y a continuación la columna y su letra y la línea que corresponde siempre al t. 122 de la PL. e.gr. V, 975A7-9[...] La traducción siempre es mía. 
Moisés llegó a Sinaí, «La gloria de Yavé parecía a los hijos de Israel como un fuego devorador sobre la cumbre de la montaña» (Éxodo 24, 17). Y cuando el «Anciano de muchós días» apareció al profeta Daniel $(7,9-10)$, estaba sentado en un trono hecho de llamas de fuego, y las ruedas eran fuego ardiente, y a sus pies corría un río de fuego[...] Todo lo que toca a la divinidad, todo lo que le es próximo, todo lo que la rodea participa del misterio del fuego. El carro del Señor descrito por Ezequiel $(1,4,13,27-28)$ se mueve en medio del fuego y de brasas ardientes. Los ángeles, mensajeros y ministros del Altísimo, son un fuego que quema (ó poión tous angélous autou pneúmata kaí toús leitourgoús autou pir flégon). ${ }^{14}$ Además Isaías no es admitido a dialogar con Yavé Sebaot a quien ha visto con sus ojos, hasta que un Serafín coja con unas tenazas un carbón encendido del altar y toque los labios impuros de Isaías: «Mira, esto ha tocado tus labios, tu culpa ha sido quitada y borrado tu pecado» (Isaías 6, 6-7).

Todos estos textos del Antiguo Testamento tienen eco en tantos lugares del Nuevo que sería muy largo y tedioso ir entresacando de aquí y de allá el correspondiente pasaje. Pero no soy capaz de silenciar las palabras que Xto. nos transmite en el Evangelio de Lucas (12, 49): «Ignem veni mittere in terram, et quid volo nisi ut accendatur?». Este versículo evangélico ha representado un papel importante en la especulación erigeniana. ${ }^{15}$ Parece como si nos encontráramos con un Jesucristo convertido en el nuevo Prometeo o en el nuevo Orfeo que sembraran fuego en la tierra y después, como un pirómano cualquiera, lo prendiera fuego. «Sólo quiero que se encienda» ${ }_{C}$ Cómo debemos entender este deseo?. F. Ravaisson comentando este pasaje nos dice que «esta voluntad es la llamada al reino del Espíritu, que Cristo anunció como Aquel al que estaba reservado anunciar finalmente, sin enigmas y sin figuras, toda verdad». ${ }^{16} \mathrm{Al}$ citar aquí a Félix Ravaisson no es una huída hacia adelante $o$ un querer salirnos del tema. No, sino más bien, todo lo contrario, porque este filósofo espiritualista contribuyó en gran medida a la iniciación de los estudios erigenianos en los nuevos tiempos y, además, porque su Testament philosophique discurre todo él por el tema del fuego, como si estuviese siempre pisando ascuas. ${ }^{17}$

Las liturgias cristianas han sabido explotar, de manera elocuente y dramática; el tema bíblico del fuego. Algunos ejemplos van a permitirnos ilustrar estos propósitos. Una antífona de origen griego que la liturgia romana utilizaba antes para la fiesta de la Circuncisión de Xto:, decía así: «En la zarza que vio Moisés y que no se consumía, reconocemos tu virginidad digna de toda alabanza. ¡Oh Madre de Dios, intercede por nosotros!». ${ }^{18}$ María, efectivamente, guardó en su seno el fuego de la divinidad y este fuego, como el que contempló Moisés y que dejó intacta la zarza, no destruyó su virginidad. Así aparece en Gregorio de Nissa, ${ }^{19}$ en Proclo de Constantinopla, ${ }^{20}$ en Hesicio de

14. En lugar de pyr flégon (Ps. 103,4), en la carta a los He. 1,7 leemos: pyrós flóga: «Tiene por mensajeros a los vientos, y por ministros llamas de fuego». «El que hace a sus ángeles espíritus (vientos) y a sus ministros llamas de fuego». Sagrada Biblia, ed. Nácar-Colunga, B.A.C., Madrid.

15 Periphyseon, V, 865 C 9-11; 998 A 1-3.

16 Ravaisson, F., Testament philosophique et fragments, Paris, 1933, p. 105.

17 Ibíd. o.c., pp. 91, 105, 109-110, 120.

18 «Rubum quem viderat Moyses incombustum, conservatam agnovimus tuam Iaudabilem virginitatem. Dei genitrix, intercede pro nobis», PL. 78, $741 \mathrm{C} 1-4$.

19 G. De Nisa, De vita Moysis II, 21; PG. 44, 332D; Gregorii Nysseni Opera VII, 1, p.39, pp.17-20.

20 Proclus Constantinopolitanus, Homilia I de laudibus sanctae Mariae, PG. 65, 681 A 14-15. 
Jerusalem ${ }^{21}$ y en Máximo el Confesor. ${ }^{22}$ En Xto., dice también Anastasio el Sinaita, el fuego de la divinidad está tan íntimamente unido a la humanidad que no puede ser separado de ninguna manera. ${ }^{23}$ Una oración de origen griego, que sólo la tradición latina parece haber conservado, se dirige de esta manera y con estas palabras a la Madre de Dios: «Salve, oh tú que has recibido en tus entrañas el fuego inextinguible de la divinidad. Madre inmaculada, líbranos del fuego eterno». ${ }^{24}$

Por otra parte se sabe el papel que el fuego desempeña en toda la liturgia: la llama de los cirios, los candelabros encendidos, el fuego hecho incienso, la llama que arde continuamente ante el tabernáculo. Y todos tenemos en la memoria el fuego nuevo que surge de la piedra en la noche de Pascua, como Xto. surgió de la piedra del sepulcro; y el canto a la luz que brota del fuego. En cuanto a la liturgia de Pentecostés y también en su octava, es toda ella una alabanza del fuego que descendió sobre los Apóstoles, identificado con el fuego que Jesús trajo a la tierra y que desearía vivamente ver incendiarse. ${ }^{25}$

No hay lugar para el asombro si los místicos cristianos, educados en el contexto bíblico y litúrgico que, a grandes rasgos acabamos de evocar, traduzcan a veces sus experiencias en imágenes tomadas del fuego: puesto que la divinidad es fuego, su contacto se traduce y se transforma necesariamente en una hoguera. Ya conocemos las sublimes sentencias de San Juan de la Cruz en su Llama de amor viva:

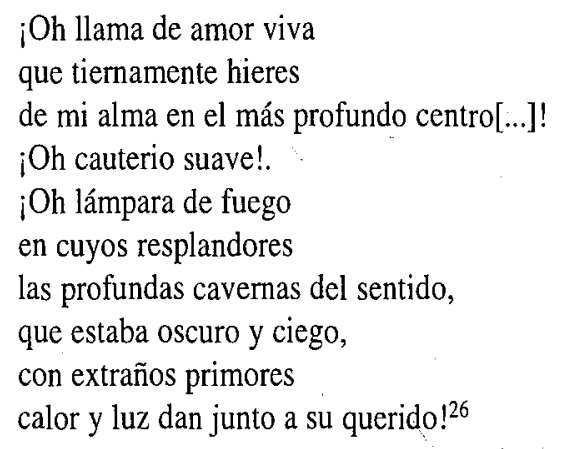

Conocemos también el Memorial que Pascal escribió «en el año de gracia de 1654», y que llevaba cosido en el forro de su jubón:

\section{FUEGO}

Dios de Abrahan, Dios de Isaac. Dios de Jacob no de los filósofos y los sabios.

Certeza, Certeza. Sentimiento, Alegría, Paz.

Dios de Jesucristo. ${ }^{27}$

\footnotetext{
21 Hesychius Hierosolimitanus, Homiliae festales V, 2; PG. 93; 1461 C 15; 1464 A 2.

22 Maximus, Ambigua ad Iohannem VI, 833; PG. 91, 1148 D 4.

23 Anastasius Sinaiticus, Viae dux XXI, 4, 20-24; PG. 89, 281 B 10-15.

24 «Ave, ignem divinitatis inextinguibilem in tuo utero accipiens!. Mater incontaminata, inextinguibili igne libera». (Ms. Paris, Bibl. nat. Lat. 10307, f. 95v).

25 PL. 78, 114 B $4-7$.

26 San Juan De La Cruz, La llama de amor viva. Obras poéticas, libros Río Nuevo, San Cugat del Vallés, Barcelona, 1982, p. 153.

27 Pascal, Oeuvres complètes, Bibliothèque de La Pléiade, Paris, 1954, p. $554 .$.
} 
Los textos litúrgicos concernientes al fuego, ampliados por la liturgia y experiencia de los místicos, terminan imponiéndose de modo naturạl a la reflexión de los teólogos. San Isidoro de Péluse (s.V) en una carta dirigida al Conde Herminos, plantea la siguiente cuestión: «Por qué todo lo que es divino es designado de manera característica con el nombre de fuego?». El autor propone dos razones: primera porque el fuego ignora la parsimonia, se extiende con generosidad, -una sola lámpara puede alumbrar a mucha gente- en una palabra es áfzonos, sin mezquindad. Y esto es, según Platón en Timeo, un atributo de la divinidad. ${ }^{28} \mathrm{La}$ segunda razón es que, de los cuatro elementos, sólo el fuego tiende hacia lo alto ${ }^{29}$ Hemos de decir que es muy poco probable que Scoto Eriúgena haya conocido la Carta a Herminos; pero podría, en cambio, haber tenido conocimiento de las siguientes etimologías que nos aporta San Gregorio Nacianceno: «El vocablo Zeós, según los expertos en etimologías, deriva bien del verbo Zéein (correr), bien del verbo Aízeiv (quemar), porque Dios está en perpetuo movimiento y porque devora las inclinaciones perversas: por esta razón se le llama fuego devorador (Pur katavalískon: Deut. 4,24)». ${ }^{30} \mathrm{He}$ dicho que Scoto Eriúgena pudo haber conocido estas interpretaciones del Teólogo, porque muchas veces hace referencia a la primera de las etimologías (Zéein = correr). ${ }^{31}$ Sin embargo, que yo sepa, jamás hace la menor alusión a la segunda, es decir a que el término Zeós provenga del verbo Aízein (quemar).

De todas las maneras y cualesquiera que sean las fuentes donde haya ido a beber Scoto Eriúgena, el verdadero conductor y maestro que inició a Eriúgena en la metafísica del fuego fue indudablemente Dionisio. En Coelestis Hierarchia (XV, 2) el Pseudo-Dionisio se pregunta ipor qué las Escrituras recurren al fuego para describir esta Esencia que está por encima de toda esencia y que llama «Thearchia»? Para responder a esta pregunta el maestro místico analiza las propiedades del fuego sensible y las enumera presentándolas por parejas antitéticas. El fuego está en todas las cosas y se insinúa en todas las cosas, pero está separado de todas las cosas. Es a la vez luminoso y oculto porque, incognoscible en sí, se manifiesta en las materias que inflama. Tiende hacia lo alto, pero se insinúa también por todos los poros de la materia. Es sorprendente e inabarcable. Está presente en todas las cosas, pero lo está de manera invisible. Parece no existir y, sin embargo, sólo es necesario un simple frotamiento para hacerlo aparecer. No experimenta ningún desgaste, y sin embargo no cesa de comunicarse. ${ }^{32}$

\section{EL FUEGO IMAGEN DE DIOS}

Es precisamente esta actitud para recibir y para reprimir en sí propiedades contrarias, lo que hace del fuego el elemento privilegiado cuando se trata de significar lo divino. Gaston Bachelard insiste en el carácter «dialectizado» del fuego:

28 «Agazós én, agazw dé oúdeis perí oúdenós oúdépote eggígneai phzónos» Platon, Timeo, 29e.

29 PG. 78, 1124 A-B.

30 Gregorio Nacianceno, Oratio XXX (Theologica IV), 20; PG. 36, 128 A 1-6; Cfr. Oratio IV, 2; PG.35, 821 1-4.

31 Periphyseon I, $452 \mathrm{~B}-\mathrm{D}, 460 \mathrm{~A}$.

32 Pseudo-Dyonisius, Caelestis Hierarchia XV, 2; PG. 3, 328C-329C. Cfr. Obras Completas del Pseudo-Dionisio Areopagita, ed, de Teodoro H. Martín, BAC, Madrid, 1990, pp. 177-78. De todas las maneras utilizaré el texto crítico de Günter Heil y las notas doctrinales de M. de Gandillac en vol. 58 de la colección «Sources Chrétiennes», p. 166-171. 
El fuego es íntimo y es universal. Vive en nuestro corazón. Vive en el cielo. Sale de las profundidades de la sustancia y se ofrece como un amor. Vuelve a descender en la materia y se oculta, latente, contenido como el odio y la venganza. Entre todos los fenómenos es el único de verdad que pueda recibir tan nítidamente las dos valoraciones contrarias: el bien y el mal. Brilla en el Paraíso. Abrasa en el Infierno. Es dulzura y tortura. Es cocina y apocalipsis. Es placer para el niño sentado prudentemente cerca del hogar; sin embargo castiga toda desobediencia cuando se quiere jugar demasiado cerca con sus llamas. Es bienestar y es respeto. Es un dios tutelar y terrible; bueno y malo. Puede contradecirse: es uno de los principios de explicación universal. ${ }^{33}$

A pesar de las apariencias, este texto de Bachelard se sitúa en las antípodas de Dionisio y de Scoto Eriúgena. ¿Por qué?. Porque, si el fuego ocupa un lugar privilegiado en la teología erigeniana, es porque el resorte de esta teología es una tensión permanente entre afirmación (katáfasis) y negación (apófasis). Para el Pseudo-Dionisio como para Juan Escoto que se inspira en él, las negaciones tienen más valor que las afirmaciones cuando se trata del misterio de Dios. ${ }^{34}$ Si digo «Dios es bueno» seguramente estoy diciendo algo verdadero; pero si digo «Dios no es bueno», estoy diciendo algo más verdadero todavía, porque Dios transciende infinitamente la noción de bondad tal y como mi inteligencia puede aprehenderla y mi discurso la expresa. Lo mismo podemos decir de todos los atributos divinos, incluídos la verdad ${ }^{35}$ y el ser. ${ }^{36}$

¿Por qué esta superioridad de la negación sobre la afirmación?. El maestro irlandés nos lo explica:

Cuando se trata de significar la inefable esencia divina, la afirmación tiene menos valor que la negación, porque la primera (la afirmación) consiste en transferir metafóricamente al Creador lo que conviene a las criaturas, mientras que la segunda (la negación) se aplica al mismo Creador por encima de toda criatura. ${ }^{37}$

Nuestras afirmaciones referidas a la divinidad llevan consigo un riesgo de idolatría, en la medida en que atribuyen al Transcendente lo que no conviene más que al ser finito. Por lo tanto, de la misma manera que ninguna estatua, aunque sea obra de Fidias, puede representar adecuadamente lo Inconmensurable, de la misma manera ningún concepto, aunque sea el más elevado, puede expresar adecuadamente lo Infinito. El riesgo de idolatría, para el filósofo, es adorar su representación de Dios, en lugar de adorar a Dios mismo; y este riesgo se lo hace correr la teología afirmativa, no la teología negativa. En realidad, es conveniente superar las afirmaciones y las negaciones, para decir que Dios está más allá del ser y del no-ser, más allá de las cosas que son y de las cosas que no son. ${ }^{38}$ Ahora comenzamos a ver cómo el fuego, precisamente porque reconcilia en sí las pro-

33 Bachelard, G., La psycahnalyse du feu, éd. cit. pp. 19-20.

34 Periphyseon III, 684 D 4-7.

35 Periphyseon IV, 757 C-758A.

36 Periphyseon III, 684D-685A.

37 Periphyseon IV, 758 A 7-11. Cfr. Piemonte, G.A., «L'éxpression quae sunt et quae non sunt: Jean Scot et Marius Victorinus», en Jean Scot écrivain, ed. G. Allard, Montréal-Paris, 1986, 81-113.

38 Periphyseon II, III, 572 D 6-7; 681 B 14C6; Expositiones VIII, 413414. 
piedades contrarias, puede darnos una imagen - inadecuada, es verdad, pero menos inadecuada que muchas otras- de la divinidad. Comentando el pasaje de La Jerarquía Celeste $(15,2)$ en el que el Pseudo-Dionisio enumera los atributos del fuego por parejas antitéticas, escribe Scoto Eriúgena:

Si uno se pone a examinar cuidadosamente las propiedades del fuego, descubrirá, tal vez, que entre sus numerosas propiedades se encuentran imágenes evidentes de la operación divina, en la medida en que ésta puede ser expresada por imágenes sensibles. Dios está en todas las cosas, porque es el ser de todas las cosas. Se insinúa en todas las cosas, porque gobierna todas las cosas. Está separado de todas las cosas, porque es suprasensible, está más allá de todas las cosas. Brilla en la creación, porque permanecería por sí mismo oculto y desconocido, si no creaba el universo, que es como la materia en la que aparece y en la que manifiesta su acción. ¿ Y quién sería tan tonto o de tan mala fe para ignorar que, por sí mismo, Dios es inconmensurable ${ }^{39} \mathrm{e}$ invisible? En resumen, todo lo dicho en alabanza del fuego puede perfectamente, por metáfora, decirse de Dios. ${ }^{40}$

Todo lo que Scoto Eriúgena dice de Dios en este pasaje, el Pseudo-Dionisio lo había dicho del fuego. Ahora bien, una de las propiedades que hacen del fuego el elemento privilegiado para representar lo divino, es la capacidad que tiene para penetrar todas las cosas, de insinuarse en todas las cosas. Es verdad que el agua posee también esta propiedad ${ }^{41}$ pero a un nivel inferior. El fuego es, por definición, penetrante. La etimología nos dice: «El fuego es llamado pyr, y creo que es porque a través de los poros, es decir de los lugares ocultos, penetra en todas las cosas». ${ }^{42} \mathrm{El}$ fuego, o como también lo llama Scoto Eriúgena, el aire ígneo (igneus spiritus), está emparentado con las realidades incorpóreas: esto es lo que le permite penetrar, no solamente todos los espacios del mundo en el que vivimos, sino también el aire más sutil ${ }^{43}$ Su presencia no es evidente para el observador que sólo se fía de sus sentidos; como dice Dionisio es de manera invisible cómo está presente en todas las cosas: áposi parón aorátos; ${ }^{44}$ y Scoto Eriúgena lo comenta de esta manera: «El fuego está presente en todas las cosas, incluso en las que parecía ausente. Uno se figura que no está ni en el hielo ni en la nieve; sin embargo, si no estuviera ni en el hielo ni en la nieve no se fundirían bajo su acción y no tendrían parte en su color» ${ }^{45}$ La misma idea se desarrolla en el libro III del Periphyseon:

Allí donde el fuego está sustancialmente presente, también está allí la esencia del frio (frigiditas). Porque, aunque el hielo sea frío por naturaleza, ningún sabio osaría pretender que estuviera privado de la fuerza ígnea, porque ésta penetra todos los cuerpos.Allí donde arde esta fuerza ígnea, hay calor; donde no arde esta fuerza ígnea, hay frío. Y no arde más que

39. Scoto Eriúgena tradujo por immensurabilis (Expositiones XV, 203) el adjetivo griego ásjeton (á-sjetos, on= incontenible, irresistible). (PG. 3, 329 B 2).

40 Expositiones XV, 270-284.

41 Expositiones XIII. 221-234.

42 Periphyseon III, 714B 11-14. Platón considera que el término pyr es una palabra de origen bárbaro y difícil de relacionar con la lengua griega: Cratilo $410 \mathrm{a}$.

43. Periphyseon V, 902 A 15-B 6.

44 Pseudo-Dionisio, Caelestis Hierarchia XV, 2; PG. 3, 329 B 14. Cfr. ed. cast. BAC, Madrid, 1990, p. 178.

45 Expositiones XV, 250-254. 
allí donde se encuentra una materia para quemar y para consumir. Por lo tanto, los rayos del sol que se expanden en las regiones etéreas no queman: en esta naturaleza espiritual tan sutil no encuentran ninguna materia para ser quemada. Pero cuando descienden a las regiones del aire corpóreo, encuentran una materia sobre la que su acción puede ejercerse, y comienzan a inflamarse. A medida que van encontrando cuerpos más densos, su poder de quemar actúa sobre los objetos con más fuerza que la del calor que derrite o que puede derretir. ${ }^{46}$

Lo que es válido para el calor, lo es también para otra propiedad del fuego, el resplandor:

El fuego, siendo invisible en sí, engendra de suyo un rayo de luz visible. Pero este rayo de luz tal y como subsiste en la simplicidad de su naturaleza, sería igualmente invisible en sí, si no se mezclara con naturalezas corpóreas y densas. Los filósofos dicen que el rayo del sol es imperceptible para los sentidos de los animales, los cuales no pueden percibir su naturaleza sutil, pero cuando, progresivamente, descienden del cuerpo del sol hacia los elementos inferiores, comienza poco a poco a aparecer. Primero comienza a lucir en el éter muy puro, pero débilmente, porque la naturaleza del éter es muy sensible a la suya. Después, siguiendo su curso, y al llegar a las capas superiores del aire, arroja una claridad un poco más viva. Finalmente, a medida que en su descenso, penetra en las naturalezas más densas, brilla con más claridad y se deja percibir por los sentidos corporales. A su vez, este rayo de luz emite un resplandor muy brillante que llena el mundo entero, que se espande sobre la faz de todos los cuerpos y que revela la diversidad de sus colores. Este mismo resplandor, a causa de su sutileza natural, escaparía a los sentidos corporales, si no se aliara con los elementos más materiales. $^{47}$

Para que la presencia del fuego, real pero oculta, se haga manifiesta, es suficiente, dice el Pseudo-Dionisio, una simple fricción: trípsei dè...éxaífves anaphainómenon, ${ }^{48}$ que Scoto Eriúgena traduce: «attritu autem subito relucens». ${ }^{49} \mathrm{El}$ fuego está presente incluso en el agua:

No existe ningún cuerpo del que no se pueda hacer salir el fuego, siempre que éste sea provocado por un choque. Es así cómo el frotamiento de las olas produce destellos de luz, y que estas mismas olas no podrían moverse de ninguna manera si estuvieran privadas de calor. ${ }^{50}$

Por esta presencia universal y oculta en el corazón de los seres, el fuego es una imagen de Dios; del Dios del que derivan y hacia el que convergen todas las cosas según la ley neoplatónica de la procesión y del retorno. No hay ni una sola de las realidades creadas, incluso entre las más humildes, incluso entre las más deformes, en la que Dios no esté presente. Dios estả presente hasta en la materia, como el fuego está presente en el hielo y en la nieve. Así nos lo dice Scoto Eriúgena:

46 Periphyseon III, 697 B 5-C 4.

47 Ibidem II, 608 B 3-C 9.

48 Pseudo-Dionisio, Coelestis Hierarchia XV, 2; PG. 3, 329 B 15-C 1. Cfr. ed. cast. pp. 178-79.

49 Expositiones XV, 256-257.

50 Periphyseon III, 714 b 15-C 3. 
El soplo ígneo, gracias a la extrema sutileza de su naturaleza, recorre todas las cosas, llega a ser todo en todas las cosas (fit in omnibus omnia) y vuelve sobre él mismo, siendo la fuente y el origen sustancial de todas las realidades visibles. Por esto los griegos lo llaman phoitwn, es decir, «lo que vuelve». ${ }^{51}$ Efectivamente, después de haber recorrido, de manera visible y de manera invisible, todos los cuerpos del mundo, vuelve hacia sí y atrae a sí todas las cosas, las cuales tienen de él el principio de su venida al ser. Lo mismo que los santos teólogos, como dice el Pseudo-Dionisio en su Coelestis Hierarchia XV, 2, describen a menudo por el fuego la esencia divina, que está más allá del ser y de la forma, porque el fuego posee numerosas imágenes, visibles en ciertos sentidos, de lo que puede llamarse, si se nos permite la expresión, las propiedades divinas. ${ }^{52}$

Siempre fiel al pensamiento de Dionisio, escribe el filósofo irlandés:

En la medida que Dios ha impreso su semejanza en las criaturas sensibles, el espíritu ígneo es semejante a Dios. Además, Dios mismo ha dicho: «Yo soy un fuego devorador», ${ }^{53}$

Lo más asombroso, en esta metafísica del fuego, es una proposición que ya hemos visto, pero cuya osadía, en una primera lectura, no ha sido percibida lo suficiente. Vamos a insistir. Dios es como el fuego porque, nos dice Scoto Eriúgena, el fuego permanece oculto y desconocido, en tanto no arde en un cuerpo inflamado o no brilla en un cuerpo iluminado. De esta manera, Dios sería desconocido no solamente para los otros seres, sino también para sí mismo, si no hubiera creado un universo en el que pudiera aparecer y manifestarse. ${ }^{54}$ No vamos a creer que Dios haya tenido necesidad, para crear el universo, del concurso de una materia extraña: esto sería indigencia y, por lo tanto, imperfección. «La materia misma, de la que se ha escrito que Dios hizo el mundo, es de Él y está en Él, y Él mismo está en ella, en la medida en que nuestra inteligencia puede concebir que esa materia existe». ${ }^{55}$

De la misma manera, el fuego es una imagen de Dios, porque el fuego, dice el PseudoDionisio, se basta a sí mismo: aprisdeès etérou ${ }^{56}$ Scoto comenta este pasaje como sigue: «El fuego no tiene necesidad de nada: no necesita ningún elemento, porque los alimenta y los reanima a todos». ${ }^{57}$

Si Dios no puede hacerse conocer, es decir, conocerse a sí mismo, si no es creando el universo, y si, para crear el universo no necesita ninguna materia extraña, se sigue que la creación no es más que una aparición de Dios o, para emplear el lenguaje erigeniano, una teofanía. ${ }^{58}$ Escribe el filósofo irlandés:

51 Dionisio dice que el fuego vaga (foitâ=va y viene) a través de las cosas, sin mezclarse con ellas. Coelestis Hierarchia XV, 2, ed. cast. p. 178 .

52 Periphyseon III, $680 \mathrm{C} 1-13$.

53 Expositiones XIII, 431-433.

54 Ibidem XV, 277-280; Cfr. Periphyseon III, 689 A 15-B 8.

55 Periphyseon III, 679 A 7-9.

56 Coelestis Hierarchia, XV, 2; PG. 3, 329 B 11. ed. cast. p. 178.

57 Expositiones XV, 239-240.

58 Gregory, T., Note sulla dottrina delle 'Teofanie' in Giovanni Scoto Eriugena, Studi medievali, $3^{\mathrm{a}}$ serie, IV (1963)

$75-91$. 
No debemos concebir a Dios y a la creación como dos realidades distintas una de la otra, sino como una sola y misma realidad. Porque la creación subsiste en Dios, y Dios, manifestándose es, de manera admirable e inefable, creado en la creación. De invisible, se hace visible; de incomprensible, comprensible; de oculto, manifiesto; de desconocido, conocido[...]; de infinito, finito; de ilimitado, limitado; de atemporal, temporal. Creador de todas las cosas, es creado en todas las cosas. El que hizo todas las cosas, es hecho en todas las cosas. Eterno, comienza a ser. Inmutable, se mueve (para penetrar) en todas las cosas y para llegar a ser todo en todas las cosas (fit in omnibus omnia). Y no hablo aquí ni de la Encarnación del Verbo, ni de su unión con la naturaleza humana, sino de la inefable condescendencia (condescensio=sugkatábasis) de la Bondad suprema, que es Unidad y Trinidad, (y que desciende) a las cosas que son, para que sean, o mejor todavía, para que ella misma sea en todas las cosas, de la más elevada a la más humilde, siempre eterna y siempre hecha, eterna por sí y en sí; hecho por sí y en sí. Y en tanto que es eterna, no deja de ser hecha; y en tanto que hecha no deja de ser eterna; a partir de sí misma, se hace a sí misma. Porque no necesita de otra materia, que no sería ella misma y en la que se hacía ella misma. Por lo demás, Dios parecería impotente e imperfecto en sí mismo, si recibiera una ayuda de fuera para su aparición y su perfección. Por lo tanto, Dios encuentra en sí mismo el origen ${ }^{59} \mathrm{de}$ sus teofanías, —es decir, de las apariciones divinas-, porque «de Él, por Él, en Él y para Él son todas las cosas», Rom. 11, 36». ${ }^{60}$

Scoto Eriúgena no se cansa de proclamar este carácter teofánico del universo creado y vuelve sobre sus pasos para escribir:

Dios es todo lo que existe, porque hace todas las cosas y es hecho en todas las cosas (fit in omnibus), como dice San Dionisio Areopagita. Todo lo que es comprendido por el entendimiento o percibido por los sentidos no es otra cosa que la aparición del No-aparente, la manifestación del Oculto, la afirmación de Aquel que es negado, la comprensión del Incomprensible, la dicción del Indecible, el acceso del Inaccesible, la intelección del Ininteligible, el cuerpo del Incorporal, la esencia del Superesencial, el nombre del Innombrable, el peso del Imponderable, la materialización del Espiritual, la visibilidad del Invisible, la localización de Aquel que escapa al lugar, la temporàlidad del Intemporal, la definición del Infinito, la descripción del Indescriptible, etc[... $]^{61}$

Esta sucesión de antítesis evoca, en cierta medida, las propiedades antitéticas que el PseudoDionisio atribuía al fuego. Además las fórmulas fit in omnibus y fit in omnibus omnia, que se inspiran en la primera carta de San Pablo a los de Corinto (xv, 28) y que Eriúgena aplica aquí a Dios, convienen igualmente al fuego.

59 Creo sentirme autorizado para traducir occasio por 'origen', si tenemos en cuenta el hecho que, detrás de esta palabra latina, se perfila para Scoto Eriúgena la griega áformé (punto de partida de algo, causa, motivo, ocasión, áformé-ês).

60 Periphyseon III, 678 B 15-679 A 7.

61 Ibid., o. c., 633 A 7-B 7. 


\section{METAFÍSICA DEL FUEGO}

Al llegar aquí aparecen las grandes líneas de la metafísica erigeniana del fuego y lo hacen con toda claridad. Como Dios, el fuego está presente en todas las cosas, pero de manera oculta. Como Dios, el fuego, desconocido en sí, no puede ser conocido más que en sus efectos. Estos efectos son dos: el calor y la luz. ${ }^{62} \mathrm{El}$ calor tiene la primacía porque penetra los cuerpos más fácilmente y de manera más íntima que la luz. ${ }^{63}$ Pero ni el calor ni la luz pueden ser producidos por el fuego, a no ser que el fuego encuentre en su paso objetos de una naturaleza más tosca y más material que la suya. Sin materia el fuego es invisible; sin materia es frio. Ya hemos vista cómo se verifica esta ley en el cosmos. ${ }^{64}$ Nos falta ver ahora cómo se verifica en la fisiología de los animales en general y en la del hombre en particular. El fuego vital reside en el corazón. ${ }^{65}$ Por lo tanto, este fuego que produce el calor en todo el cuerpo y que proporciona la luz necesaria para la visión, ${ }^{66}$ necesita un alimento. ${ }^{67}$ Este alimento es el aire que penetra en los pulmones y gracias al cual los pulmones, como fuelles de fragua (fabrinos folles), atizan sin cesar el fuego del corazón sin permitir que se adormezca ni un solo instante. ${ }^{68}$ Por lo tanto, el aire que alimenta el corazón no es el aire en su estado puro, el elemento sutil definido por la física antigua, sino un aire mezclado de vapores húmedos, un aire cargado e impuro. ${ }^{69} \mathrm{Si}$ el aire que respiramos fuera puro, exento de mezcla, no valdría para la combustión; no podría alimentar el fuego del corazón. Privado de su alimento natural, el corazón no ardería; todo el cuerpo estaría frío porque el calor, agente del movimiento vital, lo abandonaría. Sería la muerte. ${ }^{70}$ De esta manera, se trate del universo o se trate del cuerpo humano, el fuego necesita una materia, entiéndase una materia tosca, para manifestarse. Por todo lo expuesto, tenemos que volver a decirlo: el fuego nos proporciona una imagen, es cierto que lejana, pero no engañosa, de la divinidad.

La creación entera es una teofanía. Decir esto es afirmar que cada creatura es una epifanía del fuego divino. Y cuanto más elevada sea la creatura en la escala de los seres, más está penetrada de este fuego. El filósofo, místico y poeta en este caso, se imagina un prisma con su riqueza colórica que forma una policromía y en donde pueden distinguirse hasta las esencias celestes, las criaturas más nobles de Dios, que participan en grado eminente de esta fuerza ígnea. En primer lugar están los serafines, que ocupan el lugar más alto de la jerarquía, y cuyo nombre, según el PseudoDionisio, significa «los que queman» (emprestás=incendentes) o «los que calientan» (zermainontas $=$ calefacientes). ${ }^{71}$ Pero los tronos que ocupan el tercer lugar, después de los serafines y queru-

62 Periphyseon I, II, III, 496 C 2-5; 602 C 3-8; 604 A 13-B 2; 687 C 9-11.

63 Expositiones XIII, 161-178.

64 Periphyseon II, III, 608 B 3-C 9; 697 B 2-698 B 3.

65 «ex corde, ignis videlicet sede» - «ignea siquidem virtus, cuius sedes in corde est», Peri physeon I, $480 \mathrm{C} 13$ y 498 A $9-10$.

66 Ibid., o. c., III, 730 C 11-D 6; 733 B 11-13.

67 Ibid., o. c., I, 498 A 9-B 2.

68 Ibid., o. c., V, 947 A $1-5$.

69 Ibid., o. c., V, 947 D 2-948 A 11.

70 Ibid., o. c., V, 947 C 11-D 2.

71 Pseudo-Dionisio, Coelestis Hierarchia, VII, 1; PG. 3, 205 B 4-6; ed. cast. p. 145. 
bines, también ellos son calificados de calentadores $(\text { zermaínontas }=\text { calefacientes })^{72}$ e ígneos $($ pyrious=igneos)..$^{73}$

En realidad, todos los órdenes de la jerarquía celeste, cada uno según un modo proporcionado a su dignidad, forman parte de esa policromía donde no resulta fácil establecer las fronteras cromáticas para señalar con exactitud donde comienza un color y donde acaba el otro y, en este caso, todos participan del fuego divino ${ }^{74} \mathrm{y}$, en este alarde de pirotecnia, resulta difícil establecer y distinguir lo más incandescente, o lo más ígneo, o lo más calórico. Es verdad que se trata siempre de un fuego inmaterial, y no de un fuego sensible. ${ }^{75} \mathrm{La}$ misma alma humana es de naturaleza ígnea. Nadie se asombrará que sea en el alma donde con mayor claridad aparece esta imagen, porque el hombre ha sido creado a imagen de Dios. ${ }^{76}$

Una vez más la sombra del estoicismo ronda nuestra mente y pensamos en la naturaleza del alma como fuego ${ }^{77}$ pero inmediatamente añadimos que, para Scoto Eriúgena, el alma, creada a imagen de Dios y con la semejanza del fuego divino es, como su modelo, no un fuego material, sino un fuego inteligible. ${ }^{78}$ Esta metáfora va a permitir a Eriúgena la presentación original de un argumento clásico en favor de la inmortalidad del alma, el llamado argumento «del deseo natural». Este argumento, que Tomás de Aquino utilizará, si no como prueba rigurosa, al menos a título de indicio o como signum, se presenta como un silogismo que tiene como premisa mayor la proposición siguiente: un deseo natural no tenderá hacia un fin que no existe en la naturaleza. ${ }^{79} \mathrm{Ahora}$ bien, constatamos que en todo hombre, bueno o malo, virtuoso o pecador, cristiano o pagano, está implantado un deseo natural, el de existir (naturalis appetitus essendi), de existir bien (bene essendi), de existir siempre (perpetualiter essendi) ${ }^{80} \mathrm{Y}$ puesto que este deseo natural de vida eterna no puede tener como término la nada, es necesario que el alma sea inmortal. Después de la exposición de este argumento siguiendo la lógica aristotélica, ${ }^{81}$ el filósofo del siglo IX da una versión imaginada, inspirada por su metafísica del fuego:

Si el fuego visible, que arde en una materia y que mueve sus llamas como las crines de un caballo, siempre tiende hacia lo alto; si en su auge esplendoroso, ningún movimiento es capaz de inclinarlo hacia abajo, ¿cómo creer que el fuego inteligible, el de una sustancia creada a imagen de Dios, pueda estar eternamente retenido y cautivo en los bajos fondos de la muerte y de la desdicha, hasta el punto de ser incapaz, a pesar de su apetito natural, y a pesar

72 Ibid., o. c., 205 B 11-14; ed. cast. p. 146.

73 Ibid., o. c., XV, 2; PG. 3, 329 A 3; ed. cast. p. 178.

74 Expositiones, VII, 135-145.

75 Ibid., o. c., II, 105-107.

76 Periphyseon II, 531 C 3-5.

77 Arnim, Stoicorum Veterum fragmenta, I 134 (Ciceron, Acad. post., I, 39; Tusc. Disp. I, 19); II, 775 (Commenta Lucani IX, 7); III Boethius de Sidon, fr. 10 (Macrobio, In Somnium Scipionis I, 14, 19).

78 «[... Iignis ille intelligibilis substantiae ad imaginem Dei creatae». Periphyseon V, 868 A 15-B 1. Casiodoro en De anima 3, PL. 70, 1287-88 había explicado cómo y en qué sentido alegórico había que entender esta naturaleza ignea del alma. Una definición del alma como natura ignea va a circular en Occidente por to menos hasta el siglo XII. Para los informes sobre Israel Scoto puede verse Archives d'histoire doctrinale et littéraire de Moyen Age 52(1985)p. 28 y 55.

79 Stus. Thomas, Summa Contra Gentiles II, caps. 55 y 79; Summa Theologiae I, q. 75, a.6 corpus (circa finem)

80 Esta tríada ( tò eínai, tò eû eínai, tò aeí eînai) era familiar a Máximo el Confesor, Ambigua ad Iohannem III, VI, LXI; PG. 91, 1084 B 13-C 1.

81 Periphyseon V, 868 B 4. 
de la ayuda de la gracia de su creador, ${ }^{82}$ de elevarse a las sublimes alturas de la vida bienaventurada? [...] En ọtras palabras, ¿puede admitirse como verosímil que el creador infinitamente bueno de una naturaleza dotada de razón prohiba al movimiento racional de esta naturaleza Ilegar hasta Él? ${ }^{83}$

Gilson en La philosophie au Moyen Age describe el universo metafísico de Scoto Eriúgena de la siguiente manera: «Todos los seres creados son luces[...] y cada cosa, incluso la más humilde, en el fondo no es más que una vela donde luce, aunque sea muy débilmente, la luz divina. La creación, hecha a base de muchas pequeñas lámparas que son läs cosas, no es, a fin de cuentas, más que una iluminación destinada a hacer ver a Dios» ${ }^{84}$ Gilson tenía la virtud de llegar a encontrar siempre una fórmula o una frase feliz. Su descripción del universo erigeniano está lleno de sorprendente verdad. Sin embargo, necesita una precisión en un punto concreto: la luz es una propiedad del fuego, pero es el fuego el que es sustancia ${ }^{85}$ Por consiguiente es al fuego al que hay que atribuirle le primer lugar, el puesto de honor. Lo demás es algo que brota del fuego. Puede decirse que todas las criaturas, desde la más noble a la más humilde, están penetradas, en forma de calor y de luz, por el fuego divino. Por este fuego las cosas son y son lo que son. Hay una palabras que se atribuyen al escultor Augusto Rodin y que no me resisto a citarlas: «Las cosas no son más que el límite periférico, la forma-límite de la llama a la que deben su existencia». ${ }^{86}$

El fuego divino no es sólo la fuente de donde proceden las criaturas; también es el fin último al que esas criaturas vuelven. Eriúgena, como ya lo hemos señalado, justifica el principio de este retorno por la etimología de uno de los nombres del fuego Phoitwn, Revertens, es decir, el que vuelve, el que retorna. como podemos leer en el siguiente pasaje del De divisione naturae:

Después de haber recorrido, de manera visible y de manera invisible, todos los cuerpos del mundo, el viento ígneo, vuelve sobre sí y llama a sí a todas las cosas, las cuales tienen de él el principio de su venida al ser. ${ }^{87}$

En este término último del retorno de todas las cosas a.su origen, se realizará la profecía del Apóstol: «Dios será todo en todas las cosas» (I Cor.15,28). Scoto comenta esta profecía con las siguientes palabras: «Dios será todo en todas las cosas. Es como si la Escritura dijera abiertamente: sólo Dios aparecerá en todas las cosas». ${ }^{88} \mathrm{Al}$ remplazar el verbo ser por el verbo aparecer, Scoto da a entender claramente que el retorno de las criaturas a su principio es una teofanía, la teofanía suprema. Esta teofanía, como todas las teofanías, es descrita en términos de luz y de fuego. Entonces, «la naturaleza misma con sus causas será cambiada en Dios (movebitur in Deum), de la misma manera que el aire es cambiado en luz (sicut aër movetur in luce). Porque Dios sera todo en todas las cosas, cuando ya nada será sino Dios sólo». ${ }^{89}$

Cfr. Peri physeon IV, 852 C 8-9.

Periphyseon V, 868 A 12-B 14.

Gilson E., La Philosophie au Moyen Age, Payot, Paris, 1952; ed. cast. Ed. Gredos, Madrid, 6ª reimp. 1995.

Peri,physeon I, II, 521 A 11, 605 B 2-6.

Scheler, M., Nature et forme de la sympathie, Payot, Paris, 1971, p. 120.

Peri physeon III, 680 C 5-9.

Ibid., $o . c_{\text {. }}, 1,450 \mathrm{D} 2-4$.

Ibid., o, c., V, 876 A 15-B 3; Cfr. Ibidem, III, 683 B 15-C 3. 
No vamos a concluir de lo dicho que lo Infinito y lo finito, el Creador y la criatura sean confundidos; de la misma manera que el aire convertido totalmente en luz, no pierde su naturaleza propia. ${ }^{90} \mathrm{La}$ comparación del hierro que se introduce en el fuego de la fragua, marcha pareja con el sentido anterior. El hierro no deja de ser hierro. Cuando el hierro se licúa por combustión, nada de lo que constituía su naturaleza parece subsistir: parece como si se hubiera cambiado enteramente en fuego. Eso es lo que creen los sentido. Nuestra razón, en cambio, juzga de diferente manera porque sabe que, a pesar de su licuefacción, el hierro ha conservado su propia naturaleza.

Así, pues, de la misma manera que todo el aire parece haberse convertido en luz, y que todo el hierro licuado, parece haberse convertido en ígneo o, mejor todavía, parece haberse convertido en fuego, mientras que cada uno de ellos conserva su propia sustancia; de la misma manera una inteligencia sana debe saber que después del final de este mundo, toda su naturaleza, tanto corporal como incorporal, cuando parecerá no ser otra cosa que Dios, conservará, sin embargo, la integridad de su naturaleza. De tal manera, Dios que, en sí mismo, es incomprehensible, estará, en cierta manera, comprendido en la criatura, y la criatura, por un prodigio inefable, será cambiada en Dios. ${ }^{91}$

Eriúgena encontró estas dos comparaciones, la del aire iluminado y la del hierro abrasado en Máximo el Confesor. ${ }^{92} \mathrm{Habla}$ con mucho entusiasmo de los pulcherrima paradigmata. ${ }^{93}$ Estas comparaciones le permiten, si no explicar, al menos dejar entrever cómo, en la teofanía suprema, Dios podrá ser todo en todos, sin que las naturalezas creadas sean por lo mismo aniquiladas. La vuelta de todas las cosas a su principio llevará consigo las siguientes etapas: el cuerpo será absorbido por el alma; después el alma será absorbida por el intelecto (nô̂s); finalmente el intelecto será absorbido en Dios. Estä absorción de las realidades inferiores por las superiores no va a destruir las primeras. Al contrario, la inferior se encontrará ennoblecida: para ella existir en la superior será existir más y mejor. ${ }^{94} \therefore$

El aire no pierde su sustancia cuando todo entero es transformado en luz solar, hasta el punto que no aparece en él nada más que la luz: aunque la luz no sea el aire, ni el aire la luz, es la luz la que supera al aire y es por lo que sólo parece existir la luz. Cuando el hierro, o cualquier otro metal, es fundido en el fuego, parece cambiarse en fuego, parece fuego puro, mientras que la sustancia del metal permanece intacta. Pienso que de esta manera, la sustancia corporal se cambiará en alma (in animam esse transituram), no para perder su ser, sino para ser salvada en una esencia superior. Lo mismo podemos decir del alma: será cambiada (movebitur) en intelecto, de tal manera que en este intelecto será conservada más bella y más parecida a Dios. Y no sabría hablar de otra manera del paso (transitu) de las sustancias dotadas de razón - por no decir de todas las sustancias- en Dios, en quien todas las cosas conseguirán su fin, en quien las cosas serán una. ${ }^{95}$

90 Ibid,, o. c., I, 450 A 5-12.

91 Ibid., o. c., I, 451 B 3-12.

92 Ibid., o. c., I, 450 A 4-B 2; 451 A 10-B 3. Cfr. Maximo Confesor, Ambigua ad Iohannem III, VI; PG. 91, 1076

A 2-5; 1088 D 6-8; 1140 C 6-11.

93 Periphyseon I, 451 A 10-11.

94 Ibid., o. c., V, 879 A 9-12.

95 Ibid., o. c., V, 879 A $12-\mathrm{B} 12$. 
Yo creo, después de lo que hemos dicho, que en la mente de todos nosotros existe una pregunta $y$, tal vez por ingenua, no nos atrevemos a formularla. Sería la siguiente: ¿Qué sucede con el fuego del infierno? Y rápidamente, como si el filósofo la esperase, viene la respuesta: el infierno, en cuanto lugar concreto, no tiene cabida en el universo erigeniano. Todos los textos de la Escritura que hacen alusión al infierno, deben ser entendido en sentido figurado. ${ }^{96}$ Las penas eternas de los condenados consisten en los remordimientos de sus conciencias y en la vanidad de sus deseos ${ }^{97} \mathrm{El}$ fuego del infierno es una metáfora. ${ }^{98}$ La metafísica erigeniana apuesta claramente por el optimismo. Cuando un texto bíblico parece oponerse a este optimismo, el irlandés ès lo suficientemente ingenioso como para interpretar el texto en un sentido que esté en consonancià-con sus posiciones filosóficas. Un buen ejemplo es la exégesis de «la espada de fuego».

En Génesis 3, 24 leemos que Dios, después de haber expulsado a Adán del jardín del Edén, colocó un querubín a la entrada que blandía flameante espada (flammeum gladium atque versatilem), para guardar el camino del árbol de la vida. Scoto explica que el querubín designa el Verbo de Dios y luego continúa así:

En cuanto a la espada flameante, pienso igualmente, y no sin razón, que designa también el Verbo de Dios, porque el Verbo abrasa y divide. ${ }^{99}$ Abrasa nuestros pecados: 'Dios es un fuego que devora', ${ }^{100}$ y que purifica las manchas irracionales de nuestra naturaleza. Divide esta naturaleza y la separa de todo lo que, como consecuencia de la prevaricación, le ha sido sobreañadido, la altera, la desfigura y le hace perder el parecido con su creador. Esta espada, es decir el Verbo, el Hijo único, el Poder y la Sabiduría del Padre, creemos y comprendemos justamente que es cambiante (versatilis), porque, aunque inmutable por naturaleza, es movida, sin embargo, por un movimiento de su clemencia y de su misericordia inefables en favor de la salvación de la naturaleza humana. De esta manera, este querubín y esta espada flameante están siempre colocados ante los ojos de nuestra alma, quiero decir la razón y la inteligencia. ¿Por qué?. Con el fin de guardar el camino del árbol de la vida, es decir, para que no olvidemos el camino del árbol de la vida, sino que conservemos siempre la memoria de este árbol y tengamos constantemente presente ante los ojos de nuestro corazón el camino que conduce hasta allí. ${ }^{101}$

La imagen de la espada flameante no tiene nada de espantoso: se trata de una llama que purifica y de una espada que salva. Puede decirse lo mismo del fuego que acompañará la venida de Cristo al final de los tiempos, cuando aparecerá en el cielo «el signo del Hijo del hombre». ${ }^{102}$ El filósofo del renacimiento carolingio ve el acontecimiento descrito en el Apocalipsis de la siguiente manera:

[...] el signo del Hijo del hombre (es decir, el honor y la gloria de su cruz) brillará para todos. Tal vez haya que ver en esta aparición del Verbo de Dios en toda criatura la llama última 
que llenará y consumirá el mundo entero, cuando, para los buenos como para los malos, no resplandecerá otra cośa que no sea la Luz inteligible, la que ahora llena todo de manera oculta y que entonces lo hará de manera manifiesta. Esta llama, me parece, es el que hablando de sí mismo dijo: 'Yo soy un fuego devorador'. ${ }^{103}$ Devorará todas las cosas cuando sea todo en todas las cosas. ${ }^{104} \mathrm{En}$ su evangelio dice además: 'He venido a traer fuego a la tierra y mi deseo no es otro sino que arda'. ${ }^{105}$

En otras palabras, el fuego que Jesús trae a la tierra no es un fuego destructor que reduciría a la nada la creación. ¿Cómo iba el Creador a destruir lo que había creado por bondad?. Se trata de un fuego que consumirá todas las manchas y hará desaparecer todas las excrecencias parasitarias que nuestra malicia ha añadido a la naturaleza humana, desfigurando de esta manera la imagen divina. Es un fuego que restablecerá esta naturaleza en su integridad y en su bondad primordiales. Y este fuego no es otra cosa, en última instancia, que Dios mismo. Cuando el cribador soberano haya terminado de limpiar su era (Cf. Mt.3,12), el grano, es decir, la naturaleza humana en su pureza, será separado de la paja del pecado. Esta paja será quemada por la llama de la divina sentencia. Los secretos de las tinieblas serán esclarecidos (I Cor.4,5); y Dios, que será todo en todas las cosas (I Cor. $15,28)$, aparecerá en todas las cosas. ${ }^{106}$ Atrevida dialéctica que ha tratado de reconciliar el cielo y el infierno y en la que la ékpúrwsis, el abrazo de los estoicos, se ha convertido en teofanía. En su física los estóicos distinguen los principios (arjaí) y los elementos (stoijeîa): los principios no han sido producidos y son indestructibles, mientras que los elementos sos destruidos en el abrazo (ékpúrwsis). Además, los principios son incorporales y sin forma, mientras que los elementos tienen una forma.

\section{CONCLUSIÓN}

Como en todo pensamiento filosófico coherente, la metafísica erigeniana del fuego surge de una teoría del conocimiento. Scoto Eriúgena distingue cuatro aproximaciones de la verdad revelada por la Escritura y son, por orden de dignidad creciente, las siguientes:

1. Historia (sentido literal de la Escritura).

2. Moralis intelligentia (eziké)

3. Naturalis scientia (fusiké)

4. Contemplatio divinae naturae (theologia).

Por lo tanto, cada una de estas aproximaciones, cada uno de estos niveles de conocimiento, cada uno de estos «grados del saber» corresponden a uno de los cuatro elementos del mundo sensible. Porque, si podemos decir que la Naturaleza es un libro, de modo recíproco podemos concebir que el libro de la Escritura es un mundo:

103 Deut. 4, 24; Epist. ad Hebreos 12;29.

104 I Cor., 15,28.

105 Luc. XII, 49; Peri physeon V, 997 C 15-998 A 3.

106 «Purgabitur enim natura, ventilabitur vitium, recondentur substantialia grana, flamma divinae sententiae delictorum ardebit palea, illuminabuntur abscondita tenebrarum, omnia in omnibus vedebitur Deus». Periphyseon V, 1016 A 9-13. 
La Santa Escritura es un mundo inteligible, compuesto de cuatro partes, como el mundo sensible está compuesto de los cuatro elementos. La tierra, en su punto medio, en el nivel más bajo, y como en el centro de este mundo inteligible, se encuentra la Historia. En torno a ella y envolviéndola, como las aguas que rodean la tierra, se sitúa el abismo de la interpretación moral, que los griegos acostumbran a llamar éziké. En torno a la Historia y a la éziké, como en torno de las dos partes inferiores del mundo inteligible de las que hablamos, se extiende el aire de la ciencia de la naturaleza, ciencia que los griegos llaman physiké. Fuera, y por encima de todo esto, se encuentra la zona incendiada, de éter y de fuego, del cielo empíreo, es decir, la alta contemplación de la naturaleza divina que los griegos denominan Theologia. Ninguna inteligencia osaría ir más lejos. ${ }^{107}$

En perfecta sintonía con su metafísica del fuego, Scoto Eriúgena propone aquí y ahora una división de las ciencias que coloca a la teología, contemplación del fuego divino, en la cúspide de la jerarquía del saber.

\author{
Mariano Brasa Díez \\ Universidad Autónoma \\ Madrid
}

